\title{
Elimination of Preexistent Acetylcholine Receptor Clusters Induced by the Formation of New Clusters in the Absence of Nerve
}

\author{
H. Benjamin Peng \\ Department of Anatomy, University of Illinois at Chicago, Chicago, Illinois 60680
}

Acetylcholine receptors (AChRs) form clusters spontaneously in cultured Xenopus myotomal muscle cells in the absence of innervation. Innervation causes a dispersal of these clusters, as well as the formation of new clusters along the neuromuscular contact. To examine whether this dispersal process is dependent upon the presence of the nerve or can be effected by the formation of new clusters alone, we examined the stability of the preexistent clusters during the formation of new $A C h R$ clusters induced by basic polypeptide-coated latex beads. These beads cause a rapid development of clusters in cultured Xenopus muscle cells, and the size and the number of clusters can be experimentally manipulated by varying the size and number of beads applied to the culture. Accompanying the bead-induced formation of new clusters was an observed suppression of preexistent clusters, as shown by fluorescence microscopy after staining with rhodamine-conjugated $\alpha$-bungarotoxin. This process of extrabead cluster removal can be speeded up by treating the cultures with more beads or using beads of larger diameter. Furthermore, if the beads are applied before the spontaneous $\mathrm{AChR}$ clustering, no extra-bead clusters are formed. Thus, the latex beads can mimic the nerve in both causing the formation of new clusters and the dispersal of preexistent clusters. Although the receptor clusters are dispersed by the beads, the density of diffuse receptors, as shown by autoradiography with ${ }^{125}$ I-conjugated $\alpha$-bungarotoxin does not decrease in the short-term cultures under study. This indicates that the dispersal of preexistent clusters is not due to a depletion of the surface pool of AChRs. We suggest that a change in the cytoskeleton associated with preexistent clusters may be involved in their destabilization.

During the innervation of the skeletal muscle, the nerve induces the formation of $\mathrm{AChR}$ clusters at the postsynaptic membrane (Anderson and Cohen, 1977; Chow and Cohen, 1983; Frank and Fischbach, 1979; Peng et al., 1980; Weinberg et al., 1981). This is a local effect in the sense that the clustering occurs at the site of neuromuscular interaction. In addition to this local effect, innervation also causes a change in the global distribution of AChR across the entire sarcolemma. This is seen as a decrease in the density of extrajunctional AChR (Chow and Cohen, 1983; Fertuck and Salpeter, 1974) and an elimination of extrajunctional AChR clusters (Kuromi and Kidokoro, 1984; MoodyCorbett and Cohen, 1982). Denervation causes a reversal of this effect. Thus, a rise in the density of diffuse AChR over the entire sarcolemma (Axelsson and Thesleff, 1959; Miledi, 1960) and

Received Mar. 11, 1985; revised June 24, 1985; accepted June 25, 1985.

This work was supported by National Institutes of Health Grant NS 16259 and by the Muscular Dystrophy Association.

Correspondence should be addressed to Dr. H. Benjamin Peng, Department of Anatomy, University of North Carolina at Chapel Hill, 108 Swing Bldg. $217 \mathrm{H}$, Chapel Hill, NC 27514 (the author's present address).

Copyright (C) 1986 Society for Neuroscience 0270-6474/86/020581-09\$02.00/0 the formation of extrajunctional clusters ("hot spots"; Ko et al., 1977) are seen upon denervation.

It is now generally hypothesized that the nerve induces the receptor clustering through certain neurotrophic molecules. Extracts from nervous tissues have been shown to effect receptor clustering similar to that occurring during inncrvation (Baucr et al., 1981; Buc-Caron et al., 1983; Christian et al., 1978; Jessell et al., 1979; Podleski et al., 1978; Schaffner and Daniels, 1982). This raises the question of whether the global redistribution of $\mathrm{AChR}$ is also a result of the neurotrophic action or whether the formation of ncw AChR clusters is sufficient to produce this phenomenon.

We have shown previously that, in cultured Xenopus myotomal muscle cells, the AChR clustering process can be triggered by an aneural signal-latex beads coated with basic polypeptide molecules (Peng and Cheng, 1982; Peng and Phelan, 1984; Peng et al., 1981). In addition to AChR clusters, other structural specializations characteristic of the postsynaptic apparatus, such as the basement membrane, the postsynaptic density, and the membrane invaginations, also develop at the bead-muscle contact (Peng and Cheng, 1982). Thus, this bead-muscle coculture can serve as a model system for studying the cellular processes of postsynaptic differentiation.

In this study, we examined the effect of the formation of AChR clusters induced by the latex beads on the preexistent clusters in aneural Xenopus muscle cultures. Our results clearly show that the formation of new clusters causes an elimination of preexistent clusters. This suggests that the destabilization and removal of preexistent AChR clusters can result from the formation of new clusters alone, independent of innervation.

\section{Materials and Methods}

\section{Cell cultures}

Myotomal muscle cells were isolated from Xenopus laevis embryos according to previous methods (Anderson et al., 1977; Peng and Nakajima, 1978). They were cultured on coverglass squares $(18 \times 18 \mathrm{~mm})$ in Steinberg's solution $\left(60 \mathrm{~mm} \mathrm{NaCl}, 0.7 \mathrm{~mm} \mathrm{KCl}, 0.4 \mathrm{~mm} \mathrm{Ca}\left(\mathrm{NO}_{3}\right)_{2}\right.$, $0.8 \mathrm{mM} \mathrm{MgSO}_{4}, 10 \mathrm{~mm}$ HEPES buffer, $\mathrm{pH} 7.4$ ), supplemented with $10 \%$ L-15 (Leibovitz) medium and 1\% fetal bovine serum (Gibco, Grand Island, NY). The cultures were maintained at $22^{\circ} \mathrm{C}$ for $2-3 \mathrm{~d}$ and then kept at $15^{\circ} \mathrm{C}$ to prolong their survival.

\section{Localization of the $A C h R$}

$A C h R$ clusters were localized by fluorescence microscopy. Fluorescently conjugated $\alpha$-bungarotoxin (R-BTX) was prepared by covalently linking tetramethyl-rhodamine isothiocyanate to $\alpha$-bungarotoxin using the method of Ravdin and Axelrod (1977). Muscle cultures were labeled with this ligand according to previous methods (Peng and Cheng, 1982). Following labcling, the cultures were fixed with $95 \%$ cthanol at $-20^{\circ} \mathrm{C}$ and mounted with a medium consisting of polyvinyl alcohol dissolved in PBS with 20\% glycerol (Rodriguez and Deinhardt, 1960). They were examined with a Leitz Orthoplan microscope equipped for phase-con- 
trast and rhodamine fluorescence. Micrographs were taken with an Olympus OM-2N camera on Kodak Tri-X film and developed with Kodak D-76 developer.

To localize the diffuse $A C h R$, autoradiography with radioactively labeled $\alpha$-bungarotoxin was performed. The cultures were labeled with ${ }^{125}$ I-conjugated $\alpha$-bungarotoxin (New England Nuclear, Boston, MA) at a concentration of $10^{-7} \mathrm{M}$, fixed with $2 \%$ glutaraldehyde in $0.05 \mathrm{M}$ Na-cacodylate buffer, pH 7.2, air-dried and coated with Kodak NTB2 emulsion at $1: 1$ dilution. After an exposure period of $3-10 \mathrm{~d}$ at $4^{\circ} \mathrm{C}$, the autoradiograms were developed with Kodak D-19 developer and mounted for microscopy. They were examined with bright-field and phase-contrast microscopy. To quantitate the density of silver grains, the microscopic image was projected through a $63 \times$ objective onto a video monitor with a $\mathrm{RCA}$ TC1005/N01 video camera. The grains were dotted on a transparency and the area scored was also drawn on the sheet. The density was then calculated with an IBM personal computer in conjunction with a Hipad digitizer (Houston Instruments, Austin, TX), using a program in BASIC.

\section{Induction of AChR clustering with latex beads}

Polystyrene latex beads (Polysciences, Warrington, PA) were coated with polylysine or polyornithine (Sigma, St. Louis, MO) according to previous methods (Peng and Cheng, 1982; Peng et al., 1981). Beads of three different sizes $(1.2,4.5$, and $10 \mu \mathrm{m})$ were used in this study. They were applied to muscle cultures and, after an incubation period ranging from $90 \mathrm{~min}$ to $2 \mathrm{~d}$, the cultures were examined for AChR clusters. Our previous studies have shown that these beads induce formation of new AChR clusters (Peng and Phelan, 1984). The correspondence in the position of the bead and AChR cluster was assessed with a combination of fluorescence and phase-contrast microscopy. The area of the clusters induced by the beads was calculated from fluorescence micrographs with the computer described above.

\section{Results}

\section{AChR clusters in Xenopus cultures}

$\Lambda \mathrm{ChR}$ clusters form spontancously in cultured Xenopus myotomal muscle cells (Anderson and Cohen, 1977; Anderson et al., 1977; Kidokoro and Gruener, 1982; Moody-Corbett and Cohen, 1981; Peng et al., 1980). The number and size of these clusters have varied widely from cell to cell. In our cultures, we observed an average of five clusters per cell (from 1 to 10). These ranged from submicron dots to large $A C h R$ patches that could exceed $10-20 \mu \mathrm{m}$ in width. This disparity in size made the measurement of total cluster area extremely difficult. Instead, we simply scored the number of clusters as a means of quantitating them. The large clusters, as shown in Figure 1, $a$, $b$, were found on the top or bottom of the cell, or along the cell edge, and were often composed of smaller subclusters. In our cultures, $50-100 \%$ of the cells had these large clusters, with an average of two per cell.

As we described above, latex beads coated with basic polypeptide molecules can induce the formation of AChR clusters. The size of the bead-induced clusters can be manipulated by varying the size of the beads applied to the cultures. In the fluorescence studies, we used both 4.5 and $10 \mu \mathrm{m}$ beads. Examples of these bead-induced clusters are shown in Figure 1, $c$, $d$. Similar to the spontaneously formed clusters, these clusters were composed of smaller subclusters 0.5 to $1 \mu \mathrm{m}$ in size. By comparing Figure $1, c$ and $d$, one can readily see that the clusters induced by $4.5 \mu \mathrm{m}$ beads are considerably smaller than those induced by $10 \mu \mathrm{m}$ beads. The $4.5 \mu \mathrm{m}$ bead-induced clusters occupied a mean surface area of $8.4 \mu \mathrm{m}^{2}\left(\mathrm{SD}=4.2 \mu \mathrm{m}^{2}, n=\right.$ 37 ; range, $1.4-18 \mu \mathrm{m}^{2}$ ), corresponding to a circle with a diameter of $3.3 \mu \mathrm{m}$. The clusters induced by $10 \mu \mathrm{m}$ beads had a mean surface area of $17.9 \mu \mathrm{m}^{2}\left(\mathrm{SD}=8.0 \mu \mathrm{m}^{2}, n=35\right.$; range, 5.7-38 $\mu \mathrm{m}^{2}$ ), corresponding to a circle with a diameter of $4.8 \mu \mathrm{m}$. Thus the $10 \mu \mathrm{m}$ bead-generated clusters were on the average twice as large as those generated by $4.5 \mu \mathrm{m}$ beads. These bead-induced clusters could not be visualized well with autoradiography. As shown in Figure $7, c, d$, only the periphery of these clusters is visible in the autoradiogram. This is presumably due to the fact that the bead-muscle contact is so tight (Peng and Cheng, 1982) that the photographic emulsion cannot penetrate into the cleft space.

\section{Effect of new cluster formation on the preexistent clusters}

Accompanying the formation of new AChR clusters induced by the latex beads was the disappearance of preexistent clusters. This is illustrated in Figures 2 and 3, which summarize the results of a single series of experiments using fluorescence microscopy. In controls without beads, there were, on average, five clusters per cell (Fig. 3A). These clusters were stable for the duration ( $48 \mathrm{hr}$ ) of the experiments (Figs. 2 and $3 B$ ). The disappearance of non-bead-associated clusters ("extra-bead clusters") is illustrated in Figure 2, which shows the response of individual cells treated with either 4.5 or $10 \mu \mathrm{m}$ beads. It is clear that the disappearance of extra-bead clusters depended both ori the duration of bead-muscle coculture and on the number of new clusters. Since there is a wide variation in the size of the individual bead-induced clusters, as described above, this result is made clearer by grouping the cells into categories, as is shown in Figure 3. Thus, by comparing Figure 3, $A$ and $B$, one can see that, with beads of the same size $(4.5$ or $10 \mu \mathrm{m})$, preexistent clusters were more thoroughly eliminated in $2 \mathrm{~d}$ cocultures than in $1 \mathrm{~d}$ cocultures. Beads of $10 \mu \mathrm{m}$ diameter, which induced clusters twice as large as those of $4.5 \mu \mathrm{m}$ beads, were much more effective in causing the removal of the extrabead clusters than were the smaller beads. A total climination of extra-bead clusters was seen in $2 \mathrm{~d}$ cocultures, when the number of bead-induced clusters reached 17-24 for the $10 \mu \mathrm{m}$ beads, corresponding to an average total area of $370 \mu \mathrm{m}^{2}$ for the new clusters. This was also accomplished by approximately $25-32$ clusters induced by $4.5 \mu \mathrm{m}$ beads, with an average total area of $240 \mu \mathrm{m}^{2}$.

The results presented in Figures 2 and 3 document the disappearance of all extra-bead clusters, including the large composite clusters shown in Figure 1, $a, b$, and the small punctate clusters. The effect of cluster removal is more impressive if one looks only at the large clusters, as illustrated in Figure 4, which is from the same series of experiments shown in Figures 2 and 3 . In controls not treated with beads, all cells exhibited large clusters in this batch of culture. After $24 \mathrm{hr}$ of bead-muscle coculture, only $44 \%$ of the cells with one to eight new clusters in cultures treated with $10 \mu \mathrm{m}$ beads still had large clusters, as shown in Figure $4 A$. In these cultures, cells with more than nine new clusters showed a total suppression of the large extra-bead clusters (Fig. 4A). More pronounced suppression was seen in 2 d bead-muscle cocultures (Fig. $4 B$ ). Again, this process depended on the duration of coculture as well as on the quantity of the new cluster formation. Thus, by comparing Figure $4, A$ and $B$, one can see that $4.5 \mu \mathrm{m}$ beads were less effective in causing this cluster removal-it took approximately twice as many $4.5 \mu \mathrm{m}$ bead-induced clusters to reach the same suppression level produced by the $10 \mu \mathrm{m}$ beads. The total area occupied by these large extra-bead clusters in each cell was highly variable, ranging roughly from 50 to $150 \mu \mathrm{m}^{2}$. Thus, a formation of approximately 10 new clusters by $10 \mu \mathrm{m}$ beads or 20 new clusters by $4.5 \mu \mathrm{m}$ beads would surpass the area of these large, preexistent clusters.

Although the results shown in Figures 2-4 were from one series of experiments, three additional series of experiments were performed, with consistent results. In addition, cells merely contacted by the beads, without developing new AChR clusters, retained their preexistent clusters. This indicates that the disappearance of extra-bead clusters is related to the formation of new clusters and is not just due to the mechanical contact of the beads. 

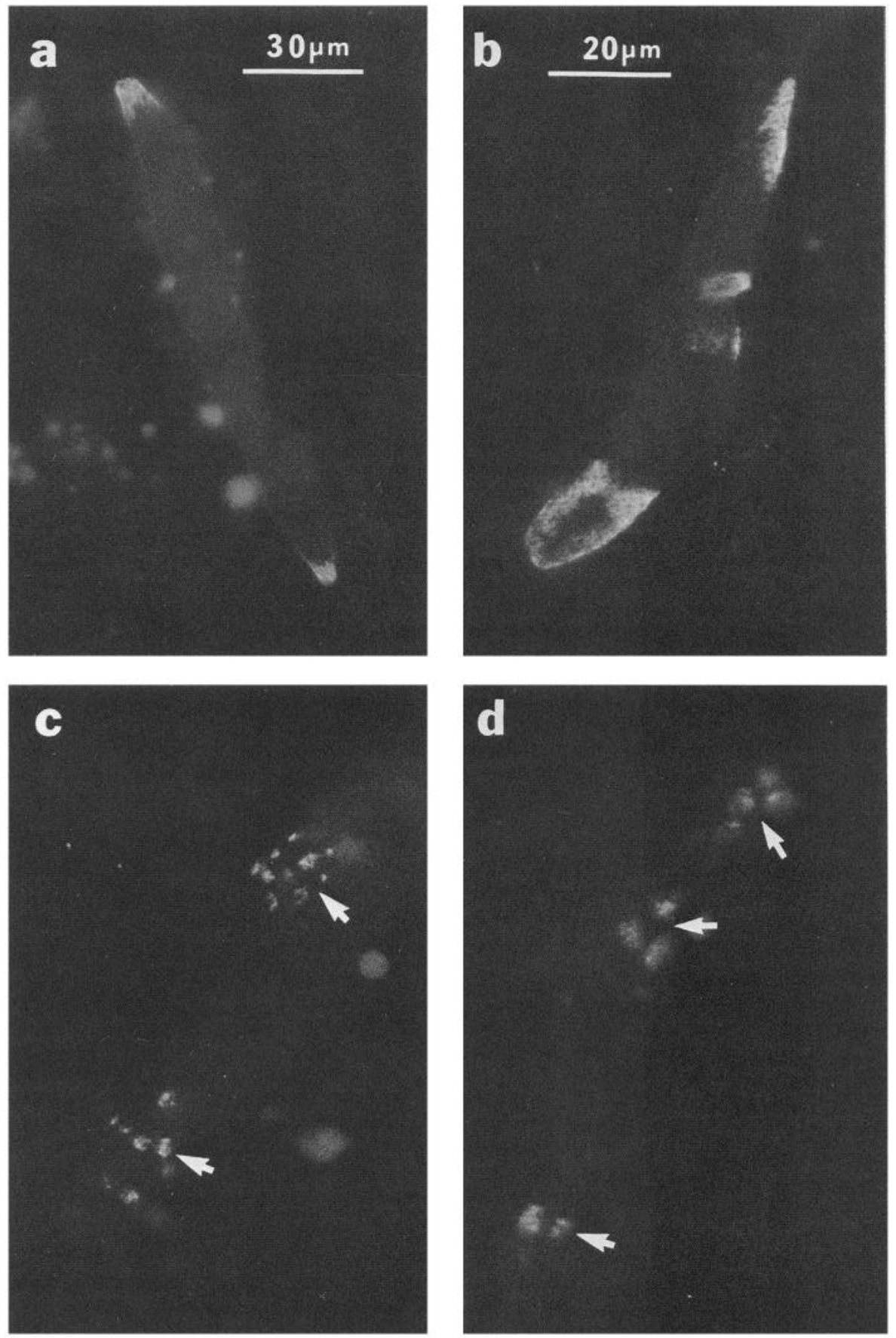

Figure 1. Examples of AChR clusters in cultured Xenopus myotomal muscle cells. $a$ and $b$, Spontaneously formed clusters ("hot spots"). These large clusters are often composed of smaller subclusters. $a$, Clusters are located at both ends of the cell, reminiscent of their distribution in vivo. $c$ and $d$, Clusters induced by polyornithine-coated latex beads. Arrows point to several groups of these bead-induced clusters. $c, 4.5 \mu$ m beads; $d, 10$ $\mu \mathrm{m}$ beads. The clusters induced by the $10 \mu \mathrm{m}$ beads are noticeably larger than those induced by the $4.5 \mu \mathrm{m}$ beads. The scale for $c$ and $d$ is the same as that for $b$.

\section{Effect of early bead application}

In view of the effect on the removal of preexistent clusters due to the formation of new clusters, we wondered whether the formation of extra-bead clusters could be totally suppressed if the beads were applied before the onset of spontaneous cluster formation. Thus, we applied polyornithine-coated beads within $3 \mathrm{hr}$ after the cells were plated. At this time most cells were well attached to the substrate, but few cells showed extensive spreading. These cells were isolated from Nieukoop-Faber (1967) stage 20-22 embryos. At these stages, the AChR are being actively incorporated into the plasma membrane both in vivo (Blackshaw and Warner, 1976; Bridgman et al., 1984; Chow and Cohen, 1983 ) and in vitro (Bridgman et al., 1984), and no AChR clusters are detected on the surface of these cultured cells until corresponding stages 32-34 (about $20 \mathrm{hr}$ after plating in our cultures; Bridgman et al., 1984). Cell spreading and the subsequent development of myofibrils appeared to be completely normal in the presence of the beads. After $2 \mathrm{~d}$ of bead-muscle coculture, the cultures were labeled with R-BTX and scored for AChR clusters. The results are summarized in Table 1. In controls not treated with beads, the cells formed an average of five clusters per cell. In contrast, the formation of extra-bead clusters, both small and large, was totally suppressed in cultures treated with beads. This result indicates that the formation of redundant clusters can be suppressed if the stimulus for the receptor clustering is presented to the cells at a sufficiently early developmental stage. In the case of Xenopus myotomal cells, this critical 
A

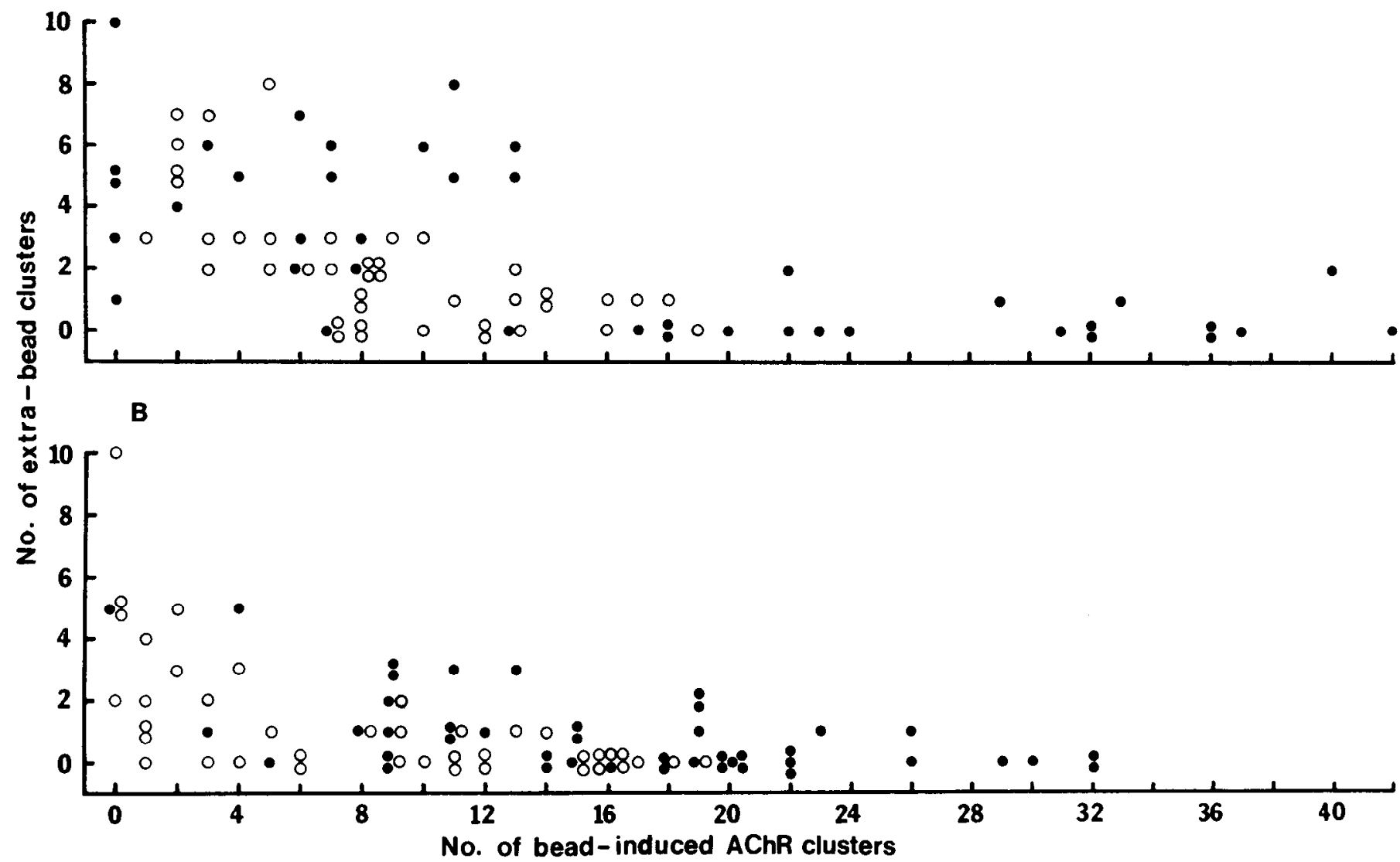

Figure 2. The relationship between the number of extra-bead clusters and the formation of new clusters induced by polyornithine-coated beads. Each point represents one cell. Filled circles, $4.5 \mu \mathrm{m}$ beads; open circles, $10 \mu \mathrm{m}$ beads. $A$, One day bead-muscle coculture. $B$, Two day bead-muscle coculture. The horizontal axis indicates the number of AChR clusters induced by each kind of bead per cell and not the number of beads contacting the muscle cell. These data are from a single series of experiments, using a single batch of cultures. $A$ represents 81 cells and 83 cells are represented in $B$.

period is presumably when the incorporation of receptors into the cell surface from the intracellular pool takes place.

\section{On the time course of the cluster removal}

Our previous study has shown that the formation of AChR clusters induced by latex beads is a rapid event (Peng and Phelan, 1984). Small punctate clusters can already be detected at $20 \%$ of the bead-muscle contacts within $90 \mathrm{~min}$ after the addition of the beads. The number of bead-induced clusters reaches saturation after $8 \mathrm{hr}$ of coculture (Fig. 5). To determine the time course of the removal of preexistent clusters, we observed the response of the large clusters to the bead-induced formation of new clusters as a function of the coculture time. Figure 5 shows the results pooled from two experiments on cultures treated with $4.5 \mu \mathrm{m}$ beads. In the absence of beads, $90-100 \%$ of the cells had large AChR clusters that were stable for at least $48 \mathrm{hr}$. In cultures treated with beads, a time-dependent disappearance in the large clusters was seen (Fig. 5). This process was already evident in bead-muscle cocultures less than 24 hr old, especially in cells with a large number $(>9)$ of bead-induced clusters, and it continued through the first $2 \mathrm{~d}$ of coculture. However, if the beads fell into an area occupied by a preexistent large cluster, as is shown in Figure 6, a reorganization of the large cluster at the bead-muscle contact was seen within a few hours, such that the fluorescence due to R-BTX labeling now conformed to the circular contour of the bead. This indicates that the formation of a new cluster is capable of causing an immediate rearrangement of preexistent clusters if they are proximal to each other.

\section{Diffuse $A C h R$}

The elimination of preexistent AChR clusters could conceivably result from a depletion of the surface AChR pool due to the formation of new clusters. Thus, we used autoradiography to examine the density of diffuse AChR at the cell surface following the formation of new clusters. Figure $7, a, b$, shows an example of a control cell not treated with beads. In addition to AChR clusters (Fig. 7a), one also sees a population of diffuse receptors on the top of the cell as shown by ${ }^{125} \mathrm{I}-\alpha$-bungarotoxin labeling (Fig. $7 b$ ). Following the treatment of polyornithine-coated beads, the clusters disappeared except at the beads (Fig. $7, c, d$ ). However, these bead-treated cells still had a population of diffuse $\mathrm{AChR}$, as shown by the presence of isolated silver grains (Fig. $7 d$ ). A quantitation of these results is shown in Table 2 . It is clear from this table that, although the extra-bead clusters disappeared rapidly, there was no concomitant loss of diffuse AChR in these short-term (1-2 d) experiments.

\section{Discussion}

In this study we have shown that, in addition to inducing the formation of new AChR clusters, basic polypeptide-coated latex beads also cause a removal of preexistent clusters (the "hot spots") in cultured Xenopus myotomal cells. The removal process depends both on the quantity and the duration of the new 


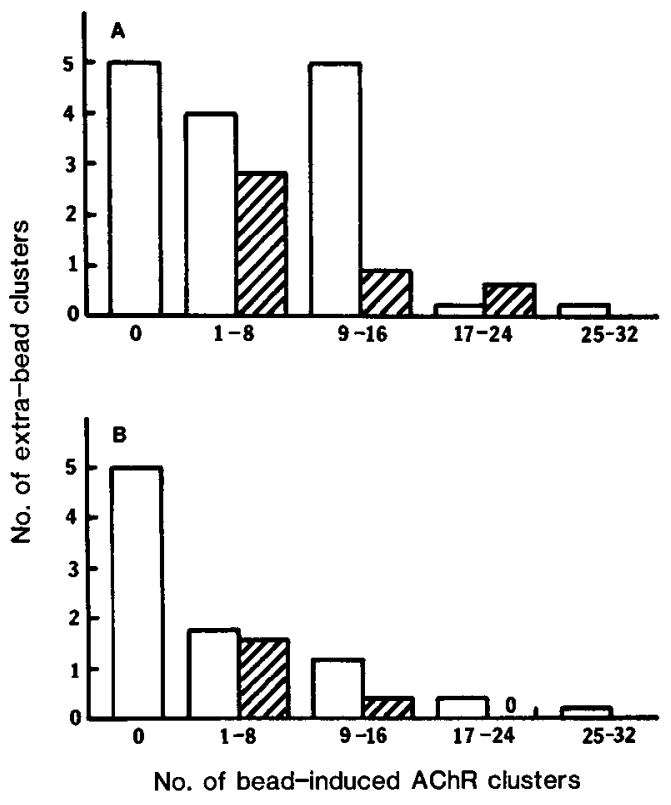

Figure 3. The elimination of extra-bead clusters in relation to the formation of new clusters induced by polyornithine-coated beads. $A$, One day bead-muscle coculture. $B$, Two day bead-muscle coculture. Open hars, $4.5 \mu \mathrm{m}$ beads; hatched hars, $10 \mu \mathrm{m}$ beads. Approximately $60-70 \%$ of the beads induced AChR clusters. The vertical axis denotes the average number of extra-bead clusters per cell, including both the large composite clusters shown in Fig. $1, a, b$, and the small punctate clusters. The zero above the horizontal axis in $B$ for $10 \mu \mathrm{m}$ beads is an actual experimental value. The data of this figure were taken from Fig. 2.

cluster formation. Thus, it can be speeded up by increasing the number or the size of new clusters, either by treating the cells with more beads or by using beads of larger diameter. Furthermore, if the beads are applied to the cells before the onset of spontaneous cluster formation, the formation of extra-bead clusters is suppressed (Table 1). Previous studies on this system have shown that the innervation causes the formation of new AChR clusters along the nerve-muscle contact (Anderson and Cohen, 1977; Moody-Corbett and Cohen, 1982; Peng et al., $1980)$ and the removal of preexistent extrasynaptic clusters (Kuromi and Kidokoro, 1984; Moody-Corbett and Cohen, 1982). Thus, the latex beads can mimic the nerve in effecting both of these functions in the postsynaptic cell. However, Kuromi and Kidokoro (1984) found that the nerve-induced cluster removal precedes the formation of new clusters. Our results, on the other hand, indicate that the bead-induced formation of new clusters occurs first. Whether this difference reflects a difference in the mechanism remains to be examined.

\section{Mechanism of cluster removal}

Studies involving cultured muscle cells have shown that the pool of preexistent AChR at the cell surface contributes, at least

Table 1. Formation of AChK clusters in the presence of latex beads

\begin{tabular}{lll} 
& $\begin{array}{l}\text { No. of bead- } \\
\text { induced clusters } \\
\text { per cell }\end{array}$ & $\begin{array}{l}\text { No. of extra- } \\
\text { bead clusters } \\
\text { per cell }\end{array}$ \\
\hline Cultures with beads & $5.3 \pm 3.0(11)$ & $0.2 \pm 0.6(11)$ \\
Control & 0 & $5.0 \pm 3.7(12)$ \\
\hline
\end{tabular}

Cultures were prepared from Nieukoop-Faber stage 20-21 embryos. Three hours after plating, $4.5 \mu \mathrm{m}$ polyornithine-coated latex beads were added to the cultures. Two days later, they were labeled with R-BTX to localize the AChR clusters. The numbers are expressed as "mean \pm SD (number of cells)."

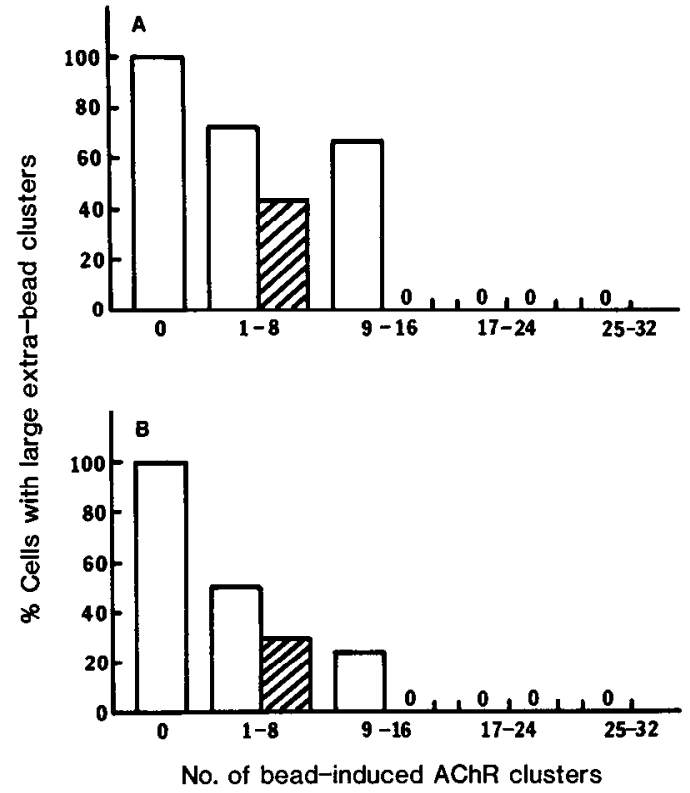

Figure 4. The elimination of large AChR clusters in relationship to the formation of new clusters induced by the beads. $A$, One day beadmuscle coculture. $B$, Two day bead-muscle coculture. Open bars, 4.5 $\mu \mathrm{m}$ beads; hatched bars, $10 \mu \mathrm{m}$ beads. The horizontal axis has the same meaning as in Fig. 2. The zeros above the horizontal axis are actual experimental values. These data are obtained from the same set of cullures used in Fig. 2. The same set of cells is represented as in Fig. 2.

in part, to the formation of new clusters (Anderson and Cohen, 1977; Kuromi and Kidokoro, 1984; Peng and Cheng, 1982). Since the AChR at the cell surface has a finite life span (half life $=52 \mathrm{hr}$ for Xenopus AChR; Brehm et al., 1983), a depletion of this surface pool due to new cluster formation can conceivably cause the removal of preexistent clusters. However, our autoradiography experiments (Table 2) have failed to show a reduction in the density of diffuse AChR even when the preexistent clusters can no longer be seen. As was pointed out above, $\mathrm{Ku}-$ romi and Kidokoro (1984) have shown that the nerve-induced cluster dispersal precedes the induction of AChR accumulation. Thus, a simple depletion of the surface AChR pool cannot account for the removal of preexisting clusters. The relatively short duration of the elimination of preexistent clusters (1-2 d), compared to the half-life of Xenopus AChR, also suggests that the latex beads affect the stability of these clusters.

This process could be mediated by a change in the properties of the cell surface, including the extracellular matrix and the plasma membrane, and/or by an intracellular mechanism. Anderson et al. (1984) recently showed that, although the nerve induces a disappearance of preexistent AChR clusters, their as-

Table 2. ${ }^{125} \mathrm{I}-\alpha$-bungarotoxin autoradiography on cultured muscle cells

Density of silver grains $/ \mu \mathrm{m}^{2}$

\begin{tabular}{ll}
\hline Culture with beads & $0.15 \pm 0.03(6)$ \\
Control & $0.14 \pm 0.02(6)$
\end{tabular}

The test culture was treated with $1.2 \mu \mathrm{m}$ polyornithine-coated beads. After $24 \mathrm{hr}$ of bead-muscle coculture, it was labeled with ${ }^{125} \mathrm{I}-\alpha$-bungarotoxin and processed for autoradiography. Only cells that showed an absence of extra-bead clusters were scored. The control was not treated with beads. The numbers are expressed as "mean grain density \pm SEM (number of cells)." The grain density of the background $\left(0.02 / \mu \mathrm{m}^{2}\right)$ has been subtracted. Non-muscle cells had a density similar to that of the background. Cultures that were pretreated with $10^{-6} \mathrm{M}$ unlabeled toxin and followed by radioactive toxin showed only low background grain density. 


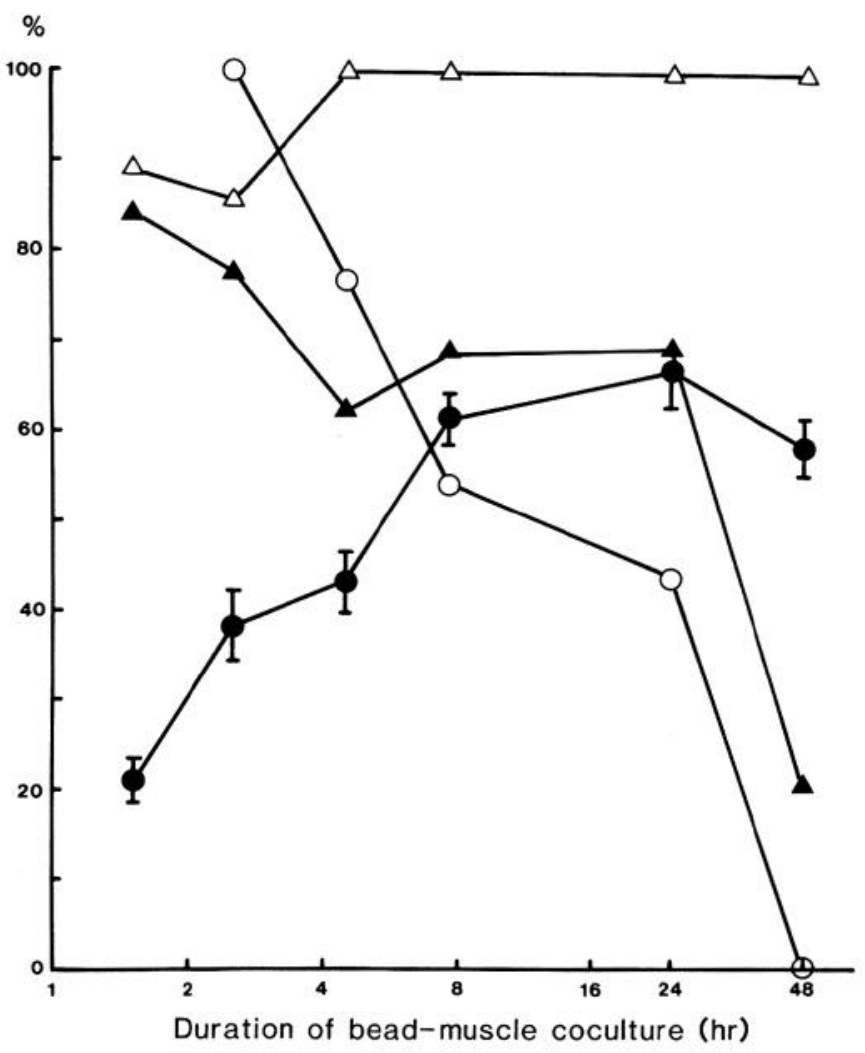

Figure 5. Time course of the formation and elimination of AChR clusters induced by the latex beads. Beads $(4.5 \mu \mathrm{m})$ coated with polyornithine were used. Solid circles indicate the formation of clusters; the vertical axis indicates percentage of beads associated with AChR clusters, as evidenced by R-BTX staining; and the bars show SEM. Other symbols show the elimination of large preexistent clusters as a function of the time of coculture and the vertical axis indicates percentage of cells with large extra-bead clusters: open triangle, cells with no new bead-induced clusters; solid triangle, cells with one to eight bead-induced clusters; open circles, cells with more than nine bead-induced clusters. Each solid circle represents the average of 40 cells and, for the other symbols, each point represents an average of 14 cells. The data are pooled from two experiments. The horizontal axis is on logarithmic scale.

sociated extracellular matrix - as evidenced by a heparan sulfate proteoglycan-still persists. This suggests that the extracellular matrix may not be involved in the destabilization of old clusters. Previously we showed that the latex bead-induced AChR clustering is reversibly inhibited by calcium antagonists or inhibitors of calmodulin (Peng, 1984). Henderson et al. (1984) also showed a similar $\mathrm{Ca}^{2+}$-dependence in nerve-induced $\mathrm{AChR}$ clustering. Thus, the stimulus for the induction of AChR clustering may elicit an increase in the intracellular $\mathrm{Ca}^{2+}$ level, perhaps by changing the membrane permeability to this ion locally. This change in $\mathrm{Ca}^{2+}$ level may transform the local process of cluster formation into a global process across the entire cell. The removal of preexistent clusters may be caused by such a rise in the cytoplasmic $\mathrm{Ca}^{2+}$ level. According to this hypothesis, the increase in the rate of cluster removal due to an increase in cluster formation (Figs. 2-4) can be expected. The site of new cluster formation is presumably protected by a mechanism of calcium sequestration. In this regard, our previous studies have shown a system of smooth endoplasmic reticulum resembling the sarcoplasmic reticulum at the site of the bead-induced AChR clustering (Peng and Phelan, 1984). This system may serve as a sink for calcium to protect the new clusters from degradation. A measurement of intracellular $\mathrm{Ca}^{2+}$ in relationship to the for-

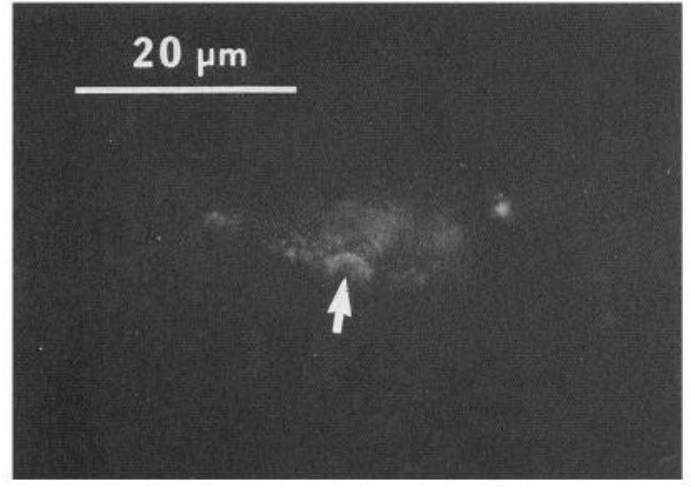

Figure 6. An AChR cluster (arrow) induced by a $4.5 \mu$ m polyornithinecoated latex bead which appeared to have landed within a large preexistent cluster. This was from a $4.5 \mathrm{hr}$ bead-muscle coculture. AChRs at the site of the bead are already arranged into the shape conforming to the circular profile of the bead.

mation of AChR clusters should provide a test of this hypothesis.

It is known that many denervation-induced changes, such as the development of ACh supersensitivity (Frank et al., 1975; Lømo and Rosenthal, 1972; Lømo and Westgaard, 1975; Purves and Sakmann, 1974), are suppressed by maintaining the electrical activity of the muscle. This may also cause an elevation of the intracellular $\mathrm{Ca}^{2+}$ level. Thus the phenomenon reported here may be related to a general cellular process involved in the development of the neuromuscular junction.

In the absence of new cluster formation, the preexistent $\mathrm{AChR}$ clusters are stable for at least 3-4 d in these cultured Xenopus myotomal cells (Moody-Corbett and Cohen, 1982). Recent studies have suggested that this stability may be related to the presence of cytoskeletal machinery underneath the cluster (Connolly, 1984; Peng, 1983; Prives et al., 1982). This machinery presumably restricts the lateral diffusion of clustered receptors (Axelrod et al., 1976; Poo, 1982). Specific components of the cytoskeleton, such as actin, vinculin, filamin, $\alpha$-actinin, and a $51 \mathrm{~K}$ protein related to the intermediate filament, have been colocalized with the AChR clusters in muscle (Bloch and Geiger, 1980; Bloch and Hall, 1983; Burden, 1982; Hall et al., 1981). Furthermore, a $43 \mathrm{~K}$ protein, originally discovered at the postsynaptic membrane in the Torpedo electric organ, is also found at the AChR cluster in muscle (Burden et al., 1983; Froehner et al., 1981; Peng and Froehner, 1985; Sealock, 1982). The destabilization of AChR clusters could result from a disruption of this cytoskeletal machinery or a dissociation of this machinery from the receptors at the cell surface. This process would allow the receptors at the cluster to mingle with the diffuse receptors by lateral diffusion. In rat myotubes, Bloch (1979) has previously shown that the preexistent $\mathrm{AChR}$ clusters can be dispersed by sodium azide treatment. Upon removal of the drug, a significant number (42\%) of clusters reformed at the original sites. This suggests that the process of cluster dispersal may not require the dismantling of the entire cytoskeletal specialization, but may only involve the removal of a certain specific component(s). Further studies, using the latex bead-muscle model and immunological methods, should reveal the key molecules involved in this process.

\section{The relationship to the development of neuromuscular contact} in vivo

Previous studies have shown that the development of the postsynaptic apparatus in the Xenopus myotomes adheres to a tight temporal scale (Blackshaw and Warner, 1976; Bridgman et al., 1984; Chow and Cohen, 1983). AChR begin to appear on the 

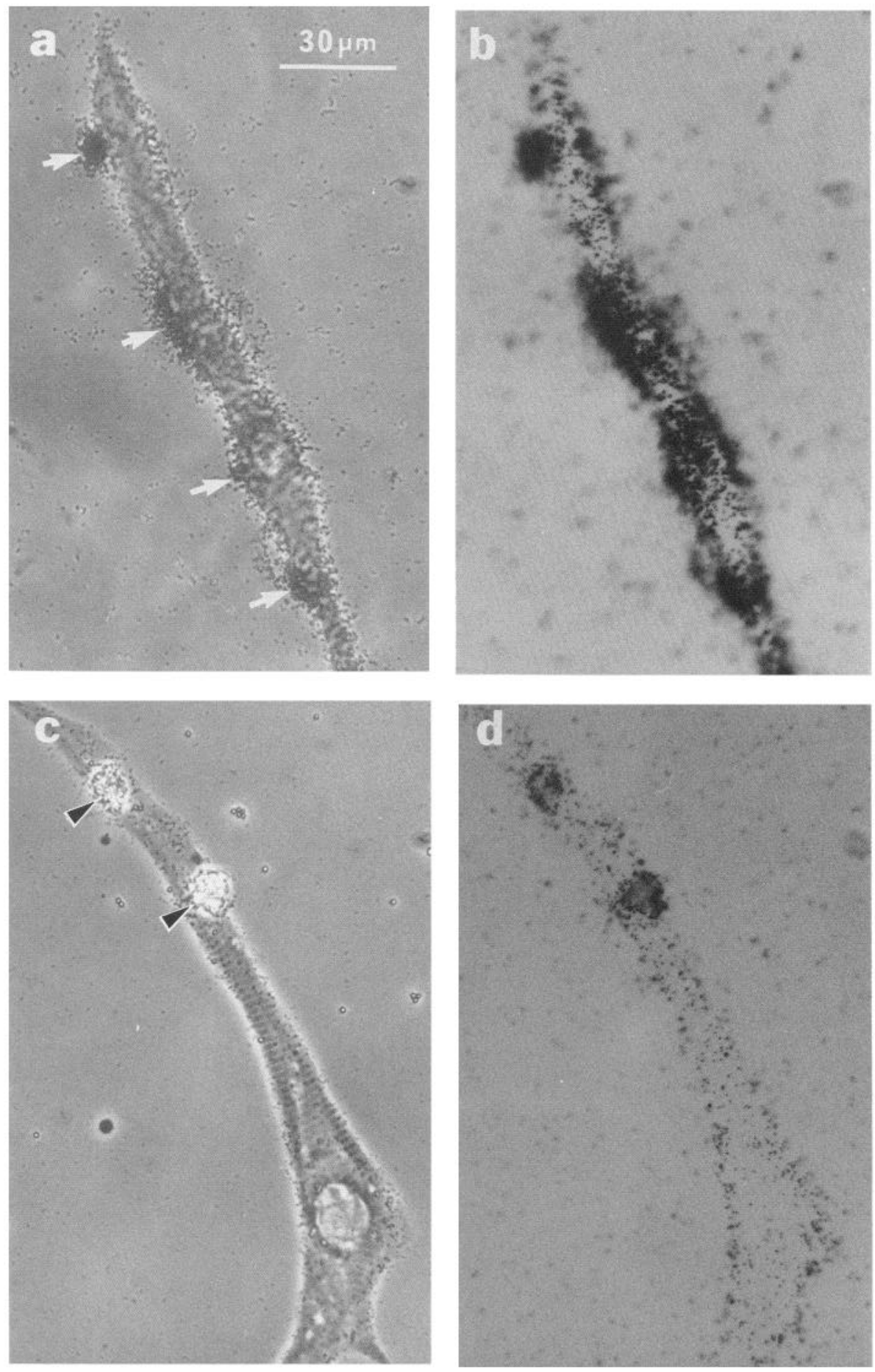

Figure 7. Autoradiography with ${ }^{125} \mathrm{I}$ - $\alpha$-bungarotoxin. $a, b$, Control with no beads added. In addition to diffuse grains (b), AChR clusters are evidenced by sites of high grain density (arrows in $a$ ). $c, d$, A cell treated with $1.2 \mu$ m polylysine-coated beads for 24 hr. No extra-bead clusters are observed in this cell. The sites of the bead clusters (arrowheads in c) are marked by the high density of silver grains $(d)$. A diffuse distribution of grains is also evident in the background. $a$ and $c$, Phase-contrast micrographs focused on the cell center. $b$ and $d$, Bright-field micrographs focused on the top of the cell.

cell surface at Nieukoop-Faber stages 19-21. At stage 24, most of the myotomes are innervated and, $3 \mathrm{hr}$ later, at stage 26 , discrete patches of high AChR density begin to appear at the ends of the myotomes, where they are innervated (Chow and Cohen, 1983). This early innervation probably prevents the development of extrajunctional AChR clusters. Recently, Bridgman et al. (1984) have shown that AChR incorporation in cultured cells isolated from embryos follows a similar schedule. They also showed that aggregates of $\mathrm{AChR}$ are first detected in cultured cells at corresponding stages 32-34. In this study, we have shown that the formation of redundant clusters can be totally suppressed if the stimulus (represented by the latex beads) for the clustering process is presented to the cells at an early stage (Table 1). This is consistent with the observation that the formation of AChR clusters occurs only at the site of innervation in Xenopus embryos (Chow and Cohen, 1983).

In contrast to the accumulation of $\mathrm{AChR}$ at the site of innervation, there is a decrease in the density of extrajunctional receptors in developing muscle. In Xenopus, after the initial surge in extrajunctional AChR density, there is a slow decline, which lasts for more than $10 \mathrm{~d}$ (Chow and Cohen, 1983). In this study, we did not observe a decline in the density of diffuse AChR clusters in the short-term bead-muscle cocultures, even though the removal of extra-bead clusters was already apparent 
(Table 2). It will now be of great interest to examine long-term cocultures in order to determine whether a decline in the diffuse AChR density can eventually be achieved in this model system.

\section{References}

Anderson, M. J., and M. W. Cohen (1977) Nerve-induced and spontaneous redistribution of acetylcholine receptors on cultured muscle cells. J. Physiol. (Lond.) 268:757-773.

Anderson, M. J., M. W. Cohen, and E. Zorychta (1977) Effects of innervation on the distribution of acetylcholine receptors on cultured muscle cells. J. Physiol. (Lond.) 268:731-756.

Anderson, M. J., F. G. Klier, and K. E. Tanguay (1984) Acetylcholine receptor aggregation parallels the deposition of a basal lamina proteoglycan during development of the neuromuscular junction. J. Cell Biol. 99: 1769-1784.

Axelrod, D., P. Ravdin, D. E. Koppel, J. Schlessinger, W. W. Webb, E. L. Elson, and T. R. Podleski (1976) Lateral motion of fluorescently labeled acetylcholine receptors in membranes of developing muscle fibers. Proc. Natl. Acad. Sci. USA 73: 4954-4958.

Axelsson, J., and S. Thesleff (1959) A study of supersensitivity in denervated mammalian skeletal muscle. J. Physiol. (Lond.) 147: 178193.

Bauer, H. C., M. P. Daniels, P. A. Pudiment, L. Jacques, H. Sugiyama, and C. N. Christian (1981) Characterization and partial purification of a neuronal factor which increases acetylcholine receptor aggregation on cultured muscle cells. Brain Res. 209: 395-404.

Blackshaw, S. E., and A. E. Warner (1976) Onset of acetylcholine sensitivity and endplate activity in developing myotome muscles of Xenopus. Nature 262: 217-218.

Bloch, R. J. (1979) Dispersal and reformation of acetylcholine receptor clusters of cultured rat myotubes treated with inhibitors of energy metabolism. J. Cell Biol. 82: 626-643.

Bloch, R. J., and B. Geiger (1980) The localization of acetylcholine receptor clusters in areas of cell-substrate contact in cultures of rat myotubes. Cell 21: 25-35.

Bloch, R. J., and Z. W. Hall (1983) Cytoskeletal components of the vertebrate neuromuscular junction: vinculin, $\alpha$-actinin, and filamin. J. Cell Biol. 97: 217-223.

Brehm, P., E. Yeh, J. Patrick, and Y. Kidokoro (1983) Metabolism of acetylcholine receptors on embryonic amphibian muscle. J. Neurosci. 3: 101-107.

Bridgman, P. C., S. Nakajima, A. S. Greenberg, and Y. Nakajima (1984) Freeze-fracture and electrophysiological studies of newly developed acetylcholine receptors in Xenopus embryonic muscle cells. J. Cell Biol. 98: 2160-2173.

Buc-Caron, M.-H., P. Nystrom, and G. D. Fischbach (1983) Induction of acetylcholine receptor synthesis and aggregation: Partial purification of low-molecular weight activity. Dev. Biol. 95: 378-386.

Burden, S. (1982) Identification of an intracellular postsynaptic antigen at the frog neuromuscular junction. J. Cell Biol. 94: 521-530.

Burden, S. J., R. L. Depalma, and G. S. Gottesman (1983) Crosslinking of proteins in acetylcholine receptor-rich membranes: Association between the $\beta$-subunit and the $43 \mathrm{kd}$ subsynaptic protein. Cell 35 : 687-692.

Chow, I., and M. W. Cohen (1983) Developmental changes in the distribution of acetylcholine receptors in the myotomes of Xenopus laevis. J. Physiol. (Lond.) 339: 553-571.

Christian, C. N., M. P. Daniels, H. Sugiyama, Z. Vogel, L. Jacques, and P. G. Nelson (1978) A factor from neurons increases the number of acetylcholine receptor aggregates on cultured muscle cells. Proc. Natl. Acad. Sci. USA 75: 4011-4015.

Connolly, J. A. (1984) Role of the cytoskeleton in the formation, stabilization and removal of acetylcholine receptor clusters in cultured muscle cells. J. Cell Biol. 99: 148-154.

Fertuck, H. C., and M. M. Salpeter (1974) Localization of acetylcholine receptor by ${ }^{125}$ I-labeled $\alpha$-bungarotoxin binding at mouse motor endplates. Proc. Nat1. Acad. Sci. USA 71: 1376-1378.

Frank, E., and G. D. Fischbach (1979) Early events in neuromuscular junction formation in vitro. J. Cell Biol. 83: 143-158.

Frank, E., K. Gautvik, and H. Sommerschild (1975) Cholincrgic receptors at denervated mammalian motor endplates. Acta Physiol. Scand. 95: 66-76.

Froehner, S. C., V. Gulbrandsen, C. Hyman, A. Y. Jeng, R. R. Neubig, and J. B. Cohen (1981) Immunofluorescence localization at the mammalian neuromuscular junction of the $M_{r} 43,000$ protein of Torpedo post-synaptic membranes. Proc. Natl. Acad. Sci. USA 78 5230-5234.

Hall, Z. W., B. W. Lubit, and J. H. Schwartz (1981) Cytoplasmic actin in postsynaptic structures at the neuromuscular junction. J. Cell Biol. 90: 789-792.

Henderson, L. P., M. A. Smith, and N. C. Spitzer (1984) The absence of calcium blocks impulse-evoked release of acetylcholine but not de novo formation of functional neuromuscular synaptic contacts in culture. J. Neurosci. 4: 3140-3150.

Jessell, T. M., R. E. Siegel, and G. D. Fischbach (1979) Induction of acetylcholine receptors on cultured skeletal muscle by a factor extracted from brain and spinal cord. Proc. Natl. Acad. Sci. USA 76 5397-5401.

Kidokoro, Y., and R. Gruener (1982) Distribution of density of $\alpha$-bungaro-toxin binding sites on innervated and noninnervated Xenopus muscle cells in culture. Dev. Biol. 91: 78-85.

Ko, P., M. J. Anderson, and M. W. Cohen (1977) Denervated skeletal muscle fibers develop discrete patches of high acetylcholine receptor density. Science 196: 540-542.

Kuromi, H., and Y. Kidokoro (1984) Nerve disperses preexisting acetylcholine receptor clusters prior to induction of receptor accumulation in Xenopus muscle cultures. Dev. Biol. 103: 53-61.

Lomo, T., and J. Rosenthal (1972) Control of ACh sensitivity by muscle activity in the rat. J. Physiol. (Lond.) 221: 493-513.

Lømo, T., and R. H. Westgaard (1975) Further studies on the control of ACh sensitivity by muscle activity in the rat. J. Physiol. (Lond) 252: 603-626

Miledi, R. (1960) The acetylcholine sensitivity of frog muscle fibers after complete or partial denervation. J. Physiol. (Lond.) 151: 1-23.

Moody-Corbett, F., and M. W. Cohen (1981) Localization of cholinesterase at sites of high acetylcholine receptor density on embryonic amphibian muscle cells cultured without nerve. J. Neurosci. 1: 596605.

Moody-Corbett, F., and M. W. Cohen (1982) Influence of nerve on the formation and survival of acetylcholine receptor and cholinesterase patches on embryonic Xenopus muscle cells in culture. J. Neurosci. 2: 633-646.

Nieukoop, P. D., and J. Faber (1967) Normal Tables of Xenopus laevis (Daudin), 2nd Ed., North-Holland, Amsterdam.

Peng, H. B. (1983) Cytoskeletal organization of the presynaptic nerve terminal and the acetylcholine receptor cluster in cell cultures. J. Cell Biol. 97: 489-498.

Peng, H. B. (1984) Participation of calcium and calmodulin in the formation of acetylcholine receptor clusters. J. Cell Biol. 98: 550557.

Peng, H. B., and P.-C. Cheng (1982) Formation of postsynaptic specializations induced by latex beads in cultured muscle cells. J. Neurosci. 2: 1760-1774.

Peng, H. B., and S. C. Froehner (1985) Association of the postsynaptic $43 \mathrm{~K}$ protein with newly formed acetylcholine receptor clusters in cultured muscle cells. J. Cell Biol. 100: 1698-1705.

Peng, H. B., and Y. Nakajima (1978) Membrane particle aggregates in innervated and noninnervated cultures of Xenopus embryonic muscle cells. Proc. Natl. Acad. Sci. USA 75: 500-504.

Peng, H. B., and K. A. Phelan (1984) Early cytoplasmic specialization at the presumptive acetylcholine receptor cluster: A meshwork of thin filaments. J. Cell Biol. 99: 344-349.

Peng, H. B., P.-C. Cheng, and P. W. Luther (1981) Formation of ACh receptor clusters induced by positively charged latex beads. Nature (Lond.) 292: 831-834.

Peng, H. B., Y. Nakajima, and P. C. Bridgman (1980) Development of the postsynaptic membrane in Xenopus neuromuscular cultures observed by freeze-fracture and thin-section electron miscroscopy. Brain Res. 196: 11-31.

Podleski, T. R., D. Axelrod, P. Ravdin, I. Greenberg, M. M. Johnson, and M. M. Salpeter (1978) Nerve extract induces increase and redistribution of acetylcholine receptors on cultured muscle cells. Proc. Natl. Acad. Sci. USA 75: 2035-2039.

Poo, M.-M. (1982) Rapid lateral diffusion of functional ACh receptors in embryonic muscle cell membranc. Naturc 295: 332-334.

Prives, J., A. B. Fulton, S. Penman, M. P. Daniels, and C. N. Christian (1982) Interaction of cytoskeletal framework with acetylcholine receptor on the surface of embryonic muscle cells in culture. J. Cell Biol. 92: 231-236. 
Purves, D., and B. Sakmann (1974) The effect of contractile activity on fibrillation and extrajunctional acetylcholine sensitivity in rat muscle maintained in organ culture. J. Physiol. (Lond.) 237: 157-182.

Ravdin, P., and D. Axelrod (1977) Fluorescent tetramethyl rhodamine derivatives of $\alpha$-bungarotoxin: Preparation, separation and characterization. Anal. Biochem. 80: 585-592.

Rodriguez, J., and F. Deinhardt (1960) Preparation of semipermanent mounting medium for fluorescent antibody studies. Virology 12:316317.

Schaffner, A. E., and M. P. Daniels (1982) Conditioned medium from cultures of embryonic neurons contains a high molecular weight factor which induces acetylcholine receptor aggregation on cultured myotubes. J. Neurosci. 2: 623-632.

Sealock, R. (1982) Visualization at the mouse neuromuscular junction of a submembrane structure in common with Torpedo postsynaptic membranes. J. Neurosci. 2: 918-923.

Weinberg, C. B., J. R. Sanes, and Z. W. Hall (1981) Formation of neuromuscular junction in adults rats: Accumulation of acetylcholine receptors, acetylcholinesterase, and components of synaptic basal lamina. Dev. Biol. 84: 255-266. 